\title{
Preskrba s stanovanji v dolini Katmanduja: javne in zasebne pobude
}

Nenačrtna rast naselij v dolini Katmanduja je rezultat hitre urbanizacije, naraščajoče revščine, visokih stroškov zemljišč ter gradnje in odvisnosti od tradicionalne prakse lastniško zgrajenih stanovanj. Ta rast povzroča ogromen stanovanjski primanjkljaj in slabe bivalne razmere. Izvajanje vladnega programa za prostor in storitve (ang. site and services programme) in tudi projekti skupnega urejanja zemljišč (ang. land-pooling projects) v 70. in 80. letih prejšnjega stoletja so koristili lokalnim lastnikom zemljišč, vendar so bila naselja zasebnega sektorja v 90. letih in na prehodu tisočletja dostopna le srednjim in višjim dohodkovnim skupinam. To je prisililo revne mestne prebivalce in ekonomsko neprivilegirane skupine v življenje $\mathrm{v}$ slumih in ilegalnih naseljih (ang. squatter settlements). Načrtovana organizacija naselij ni bila ustrezna z vidika fizične postavitve, ustvarjanja priložnosti za socializacijo in občutka pripadnosti skupnosti ter pri načrtovanju zaželene gostote prebivalstva. Obstoječi pravni in institucionalni okvir ni ustrezen in ni učinkovit pri odpravljanju teh težav. Da bi zapolnili vrzel med prizadevanji javnega in zasebnega sektorja ter ugodili visokemu povpraševanju po stanovanjih v dolini, so potrebne jasne politike in načrtovanje. To je treba uvesti, da bi povezali ponudbo stanovanj s povpraševanjem ter zagotovili sodelovanje različnih organov javnega in zasebnega sektorja pri gradbenih in stanovanjskih projektih, ki bodo vključevali revno mestno prebivalstvo. Lokalne občine bi prav tako morale biti usposobljene za upravljanje z lokalnimi viri, usklajevanje sodelujočih organov in nadzorovanje razvoja.

Ključne besede: stanovanjski primanjkljaji, dolina Katmanduja, hitra urbanizacija, zasebni sektor, državno posredovanje 


\section{Uvod}

Nepalska ustava določa pravico do primernega stanovanja kot eno temeljnih pravic vseh ljudi. Varne stanovanjske razmere prispevajo k tistim človeškim dejavnostim, ki povzročajo razvoj naroda. Prav tako vplivajo na model urbane rasti, ponujajo prostor za druženje in rekreacijo, krepijo trajnostno gospodarstvo in zlasti pomenijo družbeno in kulturno identiteto posameznih skupnosti. Domovi so materialna sredstva in psihosocialni simboli doseženega statusa, ki vplivajo na to, kako ljudje gledajo sami nase in kako jih vidijo drugi (Dunn, 2002). Ponujajo varen prostor brez zunanjega nadzora (Dupuis, 1998). Slabi stanovanjski standardi povzročajo pesimizem, pasivnost, kronični stres in splošno nezadovoljstvo (Cohen idr., 2000). Stanovanje je prav tako opredeljeno kot blago za široko porabo, predmet naložbe in socialna dobrina (Garnett idr., 1991). Stanovanje je tako kot hrana in oblačila nujna življenjska potrebščina, ker brez njega življenje $\mathrm{v}$ družbi ni mogoče. Je dolgotrajno naložbeno sredstvo, s katerim lahko ustvarjamo najemniške prihodke. Prav tako stanovanje vpliva na življenje ljudi, kriminal, socialnoekonomski razvoj in narodno identiteto. Gre za družbeno premoženje, ki ga vlada ne more prezreti.

Hitra urbanizacija in nenačrtna rast mest, postopen premik $\mathrm{v}$ osnovni gospodarski dejavnosti od kmetijstva do storitev in trgovine, kot tudi spremembe življenjskega sloga mestnih prebivalcev niso povzročili samo velikega povpraševanja po stanovanjih, infrastrukturi, socialnovarstvenih in intervencijskih storitvah, temveč so preoblikovali tudi obliko in ureditev stanovanjskih naselij v dolini Katmanduja. $V$ zvezi s tem nepalska vlada od 70. let preǰ̌njega stoletja izvaja zemljiške in stanovanjske programe, oblikuje novo zakonodajo, ustanavlja nove ustanove in spodbuja sodelovanje zasebnega sektorja. Urbani prispevki $k$ državnemu bruto domačem proizvodu znašajo $62 \%$ in bodo v okviru dvanajstega državnega petletnega razvojnega načrta za obdobje 2012-2017 (državna načrtovalska komisija, 2002) predvidoma narasli na $75 \%$. Zaradi tega trenutno vsi sektorji posvečajo vse večjo pozornost stanovanjskim standardom. V članku so s štirih vidikov analizirana prizadevanja javnih organov in zasebnih sektorjev za zagotavljanje načrtovanih stanovanj v dolini Katmanduja. Najprej so našteti številni dejavniki, ki so v dolini Katmanduja povzročili ogromne stanovanjske primanjkljaje. Nato so kritično obravnavani vladni programi za pozidavo zemljišč in gradnjo stanovanj, ki so se izvajali v 70. in 80. letih prejšnjega stoletja, ter stanovanja, ki jih je zasebni sektor zgradil v 90. letih in na prehodu tisočletja. Temu sledi prikaz številnih pomanjkljivosti pri načrtovanju in izvajanju teh procesov. $V$ nadaljevanju so te pomanjkljivosti povezane z obstoječim pravnim in institucionalnim okvirom, da bi se ugotovila njegova učinkovitost. Nazadnje pa so predlagana nekatera strateška priporočila in konkretne smernice za omilitev obstoječih problemov in zadovoljevanje prihodnjih stanovanjskih potreb v dolini.

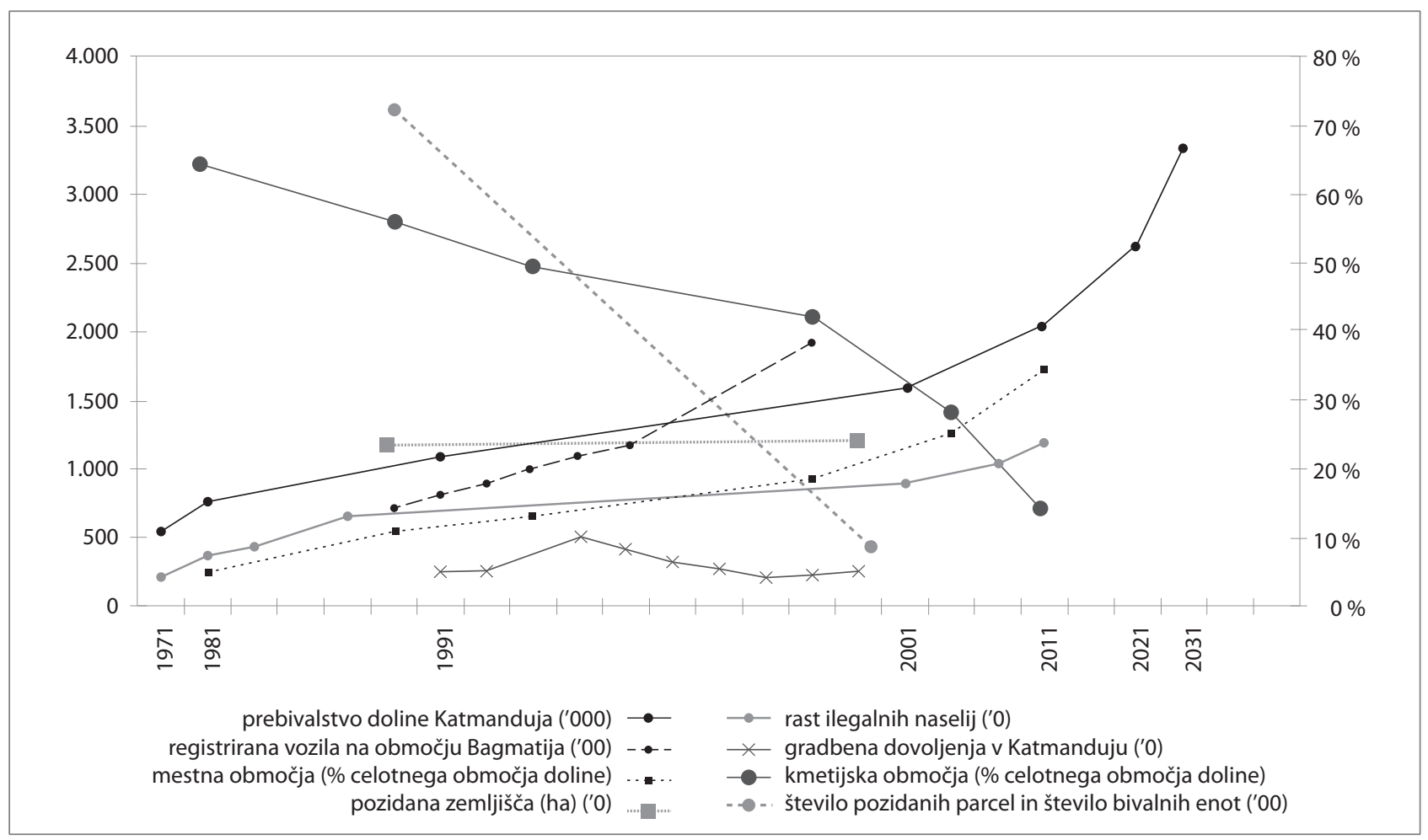

Slika 1: Hitra urbanizacija v dolini Katmanduja in nezadostna preskrba s stanovanji in infrastrukturo (vir: Shrestha in Shrestha, 2009) 


\section{Dejavniki, ki povzročajo stanovanjski primanjkljaj v dolini Katmanduja}

Ogromen stanovanjski primanjkljaj v dolini Katmanduja je nastal zaradi kombinacije treh dejavnikov. Prvič, območje je šlo skozi več prehodnih faz. Politično gledano so te faze zajemale konec dinastije Rana leta 1951, obnovitev večstrankarskega sistema leta 1990, oborožen odpor maoistov leta 1996, novejše narodno gibanje, ki je odpravilo monarhijo, in mirovno pogodbo z maoisti leta 2006. Naravne nesreče so zaradi izgube zemljišš in domov, degradacije okolja in slabega socialnoekonomskega razvoja na podeželju prav tako povzročile velike spremembe. Izjemno veliko ljudi se je preselilo v dolino Katmanduja, ker so iskali boljše ekonomske in izobraževalne možnosti ter zdravstvene, varnostne in druge storitve. Namesto da bi vlade to smer razvoja urbanizacije uredile, so $\mathrm{v}$ dolini uvedle centralistično politiko in projekte zgoščenih naselij, kar je povzročilo 6-odstotno letno rast mestnega prebivalstva (v primerjavi z državnim povprečjem, ki znaša 2,1 \%) in s tem povečanje prebivalstva $\mathrm{v}$ dolini na okrog $30,9 \%$ skupnega mestnega prebivalstva v državi. Razpoložljiva komunalno opremljena zemljišča, razširjena infrastruktura in zgrajena stanovanja ne zadovoljijo povpraševanja naraščajočega mestnega prebivalstva, vse večjega števila registriranih vozil in nenačrtnega širjenja naselij v dolini Katmanduja (slika 1). Gonilne sile, ki vplivajo na dinamičen model urbane rasti v dolini, zajemajo fizične pogoje, dostopnost javnih storitev, gospodarske možnosti, trg z zemljišči, rast prebivalstva, politične razmere, načrrte in politike (Thapa in Murayama, 2010).

Drugič, mestna revščina in vse večje razlike med bogatimi in revnimi ovirajo splošno in cenovno dostopnost stanovanj. Nepal ostaja ena najrevnejših držav na svetu z dohodkom na prebivalca v višini 20.543 NPR (278 USD med letoma 2003 in 2004; centralni statistični urad, 2004). Po podatkih desetega državnega petletnega razvojnega načrta živi na pragu revščine ali pod njim $38 \%$ ljudi: $23 \%$ v mestih in $44 \%$ na podeželju. $\mathrm{V}$ prestolnici Katmandu naj bi revno mestno prebivalstvo pomenilo približno $15,1 \%$ mestnega prebivalstva (raziskovalni inštitut Triangle, 2001). Razlike v stopnjah dohodkov so zelo velike: $60 \%$ najrevnejših prebivalcev zasluži le 5,8 \% državnega dohodka, v primerjavi s $85,4 \%$ državnega dohodka, ki ga zasluži $20 \%$ najbogatejših prebivalcev (centralni statistični urad, 1997). Le 62,5 \% gospodinjstev v dolini Katmanduja živi v svojih domovih in okoli 33,1 \% domov je na voljo za najem (centralni statistični urad, 2004). V samem Katmanduju živi približno od 30 do $35 \%$ prebivalcev v najemniških stanovanjih (Svetovna zveza za varstvo narave, 1995), od teh je $40 \%$ razmeroma revnih in ima slabšo komunalno oskrbo v primerjavi z ljudmi, ki živijo v svojih stanovanjih (Rabenau, 1990).
Raziskava 24 primerov stanovanj v Katmanduju je pokazala, da do $95 \%$ družin živi v domovih s povprečno 4,8 sobami in $11 \mathrm{~m}^{2}$ bivalne površine (podporna skupina za zavetišča Lumanti in nepalska voda za zdravje, 2000). V drugi raziskavi je primer, $\mathrm{v}$ katerem si je pet delavcev, ki delajo za dnevno plačo, za 500 NPR na mesec delilo eno najemniško sobo, ki ni bila večja od 3 3 3,4 m (trenutno 1 USD = 74,50 NPR; Prarthana, 2004). Spet druga raziskava je pokazala, da se v Katmanduju vsako leto število gospodinjstev poveča za 7.500 (raziskovalni center za neformalni sektor, 2004).

Leta 1985 je bilo v dolini le 17 ilegalnih naselij, do leta 2003 pa je to število naraslo na 64 (podporna skupina za zavetišča Lumanti, 2003). V 18 letih je prebivalstvo $v$ teh naseljih $\mathrm{z}$ 2.134 prebivalcev naraslo na 14.500 , kar pomeni skoraj sedemkratno povečanje. $V$ ilegalnih naseljih, ki so na splošno znana pod imenom naselja brez zemljǐ̌č (nep. sukumbasi basti), stanuje približno 2.600 družin oziroma 14.500 ljudi. Več kot polovica prebivalcev velikega ilegalnega naselja blizu mestnega središča je migrantov ali ljudi z nižjimi dohodki, ki so se sem preselili iz mestnega središča, ko je bilo tam veliko pritličnih stanovanj spremenjenih v trgovine (Backe-Hansen idr., 1985). Obstajalo naj bi približno 50 slumov (4.000 ljudi) brez pitne vode, stranišč ali kanalizacije (Tanaka, 1997). Okrog 60 \% ilegalnih stanovanjskih naselij je na javnih zemljiščih, preostalih $40 \%$ pa v javnih stavbah, kot so templji in gostišča (nep.pati). Nižje dohodkovne skupine, kot so delavci v tovarnah preprog, ki so zaposleni s krajšim delovnim časom (okrog 150.000 delavcev, zaposlenih za polni delovni čas, in 130.000 delavcev, zaposlenih $s$ krajšim delovnim časom; ministrstvo za prebivalstvo in okolje, 1999; USAID, 1994), in otroci, ki v Katmanduju delajo kot hišni služabniki (skupno skoraj 21.000 otrok, od teh jih je $10 \%$ mlajših od 10 let, $70 \%$ pa starih med 11 in 14 let; center za pomoč nepalskim otroškim delavcem, 1999), so zelo ranljivi. To pa ne samo zato, ker živijo in delajo v nevarnih razmerah (brez primernih bivalnih prostorov $\mathrm{v}$ hiši ter odprtih prostorov in drugih objektov zunaj hiše), temveč tudi zaradi težkega dela $\mathrm{v}$ službi, nižje stopnje izobrazbe in minimalne kupne moči.

Tretjič, do pred kratkim so bili za grajenje hiš v Nepalu odgovorni izključno posamezniki ali družine. $\mathrm{V}$ takem lastniško zasnovanem neformalnem sistemu stanovanjskih naselij posamezniki najprej kupijo parcelo s svojimi sredstvi in nato sami zgradijo hišo (Adhikari, 1998). Vso infrastrukturo, potrebno za zemljišče in hišo, v sodelovanju s sosedi uredijo postopoma. Bivalne enote se gradijo in širijo postopoma, in sicer tako kot se veča velikost družine in njeni prihodki. Več kot $90 \%$ hiš je zgrajenih na tak neformalni način. Približno $65 \%$ hiš v središču Katmanduja je zgrajenih iz opeke in blata, 64 \% jih ima urejene le začasne dovozne ceste za vozila in $26 \%$ jih ima slabe higienske razmere (Regmi in Joshi, 1988). Od 30 do $35 \%$ hiš, ki so bile v zadnjih dveh desetletjih zgrajene zunaj strnjenih stanovanjskih naselij, nima dovoznih cest, po katerih bi lahko 
do njih prišla intervencijska vozila (ministrstvo za prebivalstvo in okolje, 1999). Le $25 \%$ gospodinjstev v Katmanduju je bilo priključenih na kanalizacijo in $17 \%$ gospodinjstev ni imelo električne napeljave (nepalski nacionalni odbor za bivališča, 1996). Po podatkih nepalske državne ankete o stanovanjskih razmerah iz leta 1991, je 50,5\% bivalnih enot začasnih, 41,2 \% je srednjeročnih, le 8,3 \% je trajnih stanovanj (ministrstvo za stanovanjsko in prostorsko načrtovanje, 1996). Vse večje število slumov in ilegalnih stanovanjskih naselij je potrdilo visoko stopnjo ilegalne in neformalne gradnje stanovanj. Neustrezno zgrajena stanovanja brez osnovne infrastrukture in osnovnih socialnovarstvenih storitev potrjujejo naraščajočo stopnjo mestne revščine $\mathrm{v}$ dolini.

Zaradi teh dejavnikov je že v letu 2001 zmanjkalo stanovanj za 242.724 oseb. Ob upoštevanju stopnje naraščanja prebivalstva države v letu $1991(3,83 \%)$, bo leta 2011 predvideno število prebivalstva 2.357.312, leta 2021 pa 3.434.100. Skupno število bivalnih enot, potrebnih leta 2021, bo predvidoma okrog 435.662, kar je leta 2001 pomenilo $15 \%$ skupnega prebivalstva v dolini (odbor doline Katmanduja za mestni razvoj, 2000; preglednica 1). Okrog 3,3 \% skupnega prebivalstva doline (zdajšnjih 1.645.091) živi pod pragom revščine, kar pomeni, da na leto zasluži manj kot 11.056,80 NPR na osebo (državna načrtovalska komisija, 2005). Če domnevamo, da bo število revnega mestnega prebivalstva še naprej naraščalo po sedanji stopnji, bo leta 2021 potrebno dodatno 14.376 bivalnih enot za 113.325 revnih mestnih prebivalcev (preglednica 1).

\section{Vladni program za prostor in storitve, projekti skupnega urejanja zemljišč in stanovanjska naselja, zgrajena na pobudo zasebnega sektorja}

Stanovanjski sektor v Nepalu je bil v zadnjih nekaj desetletjih priča več razvojnim smerem $\mathrm{v}$ gradnji in izvajalski praksi: od vladno subvencionirane gradnje stanovanj v okviru programov za prostor in storitve (ang. site and services programmes) v 70. letih do projektov skupnega urejanja zemljišč (združevanje, gradnja in ponovna razdelitev) v 80. letih in gradnje zasebnih stanovanj v zadnjem desetletju. Prizadevanja Nepala, povezana z načrtovanjem rabe zemljišč in zagotavljanjem stanovanj, lahko analiziramo $s$ treh različnih vidikov, ki kažejo različne stopnje (ne)uspeha. Načrtovan razvoj se je v Nepalu začel po koncu dinastije Rana leta 1951, vendar je vlada šele leta 1977, po sprejemu zakona o razvoju mesta leta 1973 (kraljeva vlada, 1973), uvedla koncept programa za prostor in storitve, da bi priskrbela stanovanja nižjim javnim uslužbencem in širši javnosti. V tem času sta bila načrtovana dva stanovanjska programa: stanovanjski projekt Kuleswore (na 26,5 hektarja površine) za javne uslužbence brez hiš in zemljišš v dolini ter stanovanjski projekt Dallu (na 10,8 hektarja) s stanovanji za širšo javnost. Zemljišče, potrebno za ta projekta, je bilo pridobljeno iz uglednih virov. Ta prva programa nista imela velikega vpliva zaradi močnega odpora lokalnih lastnikov zemljišč, ki so za svoja zemljišča dobili nizka nadomestila (nadomestila $\mathrm{v}$ višini 10.000 NPR na ropani so se po gradnji povečala na NPR 1.600.000 na ropani; 1 ropani $=508 \mathrm{~m}^{2}$ ), zaradi razselitve prvotnih lastnikov zemljišč, slabih tehničnih in upravljavskih sposobnosti izvajalcev (odbor doline Katmanduja za mestni razvoj, ang. Kathmandu Valley Town Development Commit tee, v nadaljevanju: KVTDC), neusklajevanja med različnimi agencijami, odgovornimi za pravočasno ureditev fizične infrastrukture, zamud pri gradnji (projekta bi morala biti končana v 2 do 3 letih, vendar je bilo za to potrebnih več kot 10 let) in neustrezne ocene stroškov zaradi velikih zamud pri gradnji. Projekt Dallu so morali med narodnim gibanjem leta 1990 preoblikovati v projekt skupnega urejanja zemljišč, in sicer zaradi zahtev domačinov, naj se sprostijo njihova zemljišča ali kompenzirajo po tržni stopnji, ki je bila 40-krat višja od tiste, ki jo je predlagala vlada. Da bi rešila problem stanovanjskega primanjkljaja, je vlada leta 1982 v Galfutarju na 14,5 hektarjih zemljišč, ki so bila pridobljena z obvezno prodajo, uvedla drug stanovanjski projekt. Po parceliranju zemljišč in ureditvi infrastrukture za vsako parcelo je vlada določila ceno 18.000 NPR na parcelo, velikosti 4 anna $\left(127 \mathrm{~m}^{2}\right)$, in dala prednost pri nakupu prvotnim posestnikom, da bi preprečila njihovo razselitev, do katere je prišlo pri stanovanjskem projektu Kuleswore.

Preglednica 1: Stanovanjske enote, potrebne za predvideno število prebivalstva leta 2021

\begin{tabular}{lcccc}
\hline Kategorija & $\begin{array}{c}\text { Osebe } \\
\text { brez } \\
\text { stanovanja }\end{array}$ & $\begin{array}{c}\text { Osebe } \\
\text { na } \\
\text { gospodinjstvo }\end{array}$ & $\begin{array}{c}\text { Bivalne enote, } \\
\text { potrebne za revno } \\
\text { mestno prebivalstvo } \\
\text { (pod pragom revšcine) }\end{array}$ & $\begin{array}{c}\text { Skupno število } \\
\text { potrebnih } \\
\text { bivalnih enot }\end{array}$ \\
\hline stanovanjski primanjkljaj v letu 2001 & 242.724 & 5 & 1.602 & 48.545 \\
\hline potrebna stanovanja (2001-2011) & 739.153 & 5 & 4.878 & 147.831 \\
\hline potrebna stanovanja (2011-2021) & 1.076 .788 & 4,5 & 7.896 & 239.286 \\
\hline $\begin{array}{l}\text { Skupno število potrebnih } \\
\text { novih stanovanj v letu 2021 }\end{array}$ & $/$ & $/$ & 14.376 & 435.662 \\
\hline
\end{tabular}

Vir: povzeto od odbora doline Katmanduja za mestni razvoj (2000) 
Tako je bilo prodanih samo $50 \%$ parcel, preostale so bile v treh dneh prodane na javni dražbi.

Zaradi povečanega nezadovoljstva lastnikov zemljišč je KVTDC po sprejemu zakona o razvoju mesta leta 1988 na podlagi udeležbenega pristopa sprejel še dva modela prostorskega razvoja: usmerjeni prostorski razvoj (ang. Guided Land Development, v nadaljevanju: UPZ) in skupno urejanje zemljišč (ang. Land Pooling). V okviru UPZ so izboljšali dovozne poti oziroma zgradili nove na prej nedostopnih zemljišcih $s$ pomočjo prispevkov lastnikov zemljiřčc (ministrstvo za stanovanjsko in prostorsko načrtovanje, 1988). V okviru programa UPZ je bil načrtovana gradnja $475 \mathrm{~km}$ cest, od teh pa je bilo do zdaj zgrajenih $300 \mathrm{~km}$. Upravičenci so prispevali 170 hektarjev zemlje v vrednosti $2.800 .000 \mathrm{NPR}$, medtem ko je vlada v program vložila samo 70 milijonov NPR (KVTDC, 2002). V zadnjem desetletju in pol je bilo v okviru 11 dokončanih projektov skupnega urejanja zemljišč uspešno izboljšanih približno 240 hektarjev zemljišč ter zagotovljenih 7.184 stanovanjskih enot in drugih parcel za 5.980 lastnikov zemljišč (1988-2003, preglednica 2). Ti dokončani projekti so prav tako prispevali skupno 82,27 hektarja zemlje za ceste, odprte prostore in rezervne parcele. Vsi stroški razvoja, vključno z infrastrukturo, so bili kriti tako, da so rezervne parcele (skupno 18,98 hektarja) prodali najboljšemu ponudniku.

Projekti skupnega urejanja zemljišč v dolini postajajo vse bolj priljubljeni in so model, ki ga imajo prebivalci najraje. To pa ne samo zato, ker so stroški gradnje nižji kot pri drugih oblikah tovrstnih posegov, temveč tudi zato, ker si jih obenem delijo vsi lastniki zemljišč. Vladi je brez finančne obremenitve uspelo zagotoviti komunalno opremljene parcele, lastniki zemljišč pa so v zameno za del svojega zemljišča dobili parcele z voznimi cestami, odprtimi prostori in drugimi objekti v soseski. Poleg tega so lokalne nepremičninske agencije in posamezni nepremičninski posredniki med letoma 1971 in 1981 v občinah Katmandu in Lalitpur dali na voljo več kot 1.270 hektarjev zemljišč v stanovanjske namene (Halcrow Fox Associates idr., 1991). V primerjavi z vladnimi prizadevanji je to pomemben prispevek. Zasebni lastniki prav tako ponujajo najemniška stanovanja, ki zadoščajo stanovanjskim potrebam okrog $25 \%$ celotnega mestnega prebivalstva. V mestnem območju Katmanduja okrog $28 \%$ prebivalstva živi v najemniških stanovanjih.

Sredi 90. let prejšnjega stoletja je vlada začela spodbujati vlaganja zasebnega sektorja v razvoj zemljišč in gradnjo stanovanj ter leta 1997 sprejela zakon o lastništvu stanovanj, ki je bil zaradi pravnih in administrativnih ovir dokončan leta 2003. V dveh letih (2003-2005), je KVTDC odobril kar 15 gradbenih podjetij za gradnjo stanovanjskih enot (samostojnih hiš, dvojčkov in različnih stanovanj) v dolini. $\mathrm{V}$ triletnem obdobju je bilo v sklopu 14 zasebnih stanovanjskih programov zgrajenih okrog 965 stanovanj na 254,3 ropanija zemljišč. Ker je javnost program izjemno dobro sprejela, se je pri nepalskemu združenju za načrtovanje rabe zemljišč in gradnjo stanovanj od takrat registriralo kar 150 nepremičninskih podjetij. Od teh jih je okrog 40 do 50 registriranih za stanovanjsko gradnjo. Sodelujejo pri različnih gradbenih projektih, razlikujejo pa se po obliki gradnje, zmogljivostih in cenah. Nekaj stanovanjskih naselij je še v fazi načrtovanja, druga se gradijo in tretja so $\mathrm{v}$

Preglednica 2: Dokončani stanovanjski projekti v dolini Katmanduja

\begin{tabular}{lcccccccc}
\hline Ime projekta & $\begin{array}{c}\text { Projektna } \\
\text { površina } \\
(\text { ha) }\end{array}$ & $\begin{array}{c}\text { Parcele } \\
(n)\end{array}$ & $\begin{array}{c}\text { Lastniki } \\
\text { zemljišč } \\
(n)\end{array}$ & $\begin{array}{c}\text { Obdobje } \\
\text { izvajanja }\end{array}$ & $\begin{array}{c}\text { Predviden } \\
\text { čas trajanja } \\
\text { (leta) }\end{array}$ & $\begin{array}{c}\text { Končano } \\
\text { (leta) }\end{array}$ & $\begin{array}{c}\text { Zamuda } \\
\text { (leta) }\end{array}$ & Izvajalec \\
\hline Sainbu & 22,5 & 760 & 536 & $1991-2003$ & 5 & 12 & 7 & TDC, Lalitpur \\
\hline Dallu & 20 & 691 & 455 & $1991-2003$ & 5 & 12 & 7 & KVTDC, Katmandu \\
\hline Kamal Vinayak & 7,3 & 205 & 170 & $1991-1996$ & 2 & 5 & 3 & TDC, Bhaktapur \\
\hline Gongabu & 14,4 & 406 & 376 & $1988-1996$ & 4 & 8 & 4 & TDC, Katmandu \\
\hline Nayabazar & 44,25 & 1.569 & 1.312 & $1995-2003$ & 4 & 8 & 4 & KMC \\
\hline Liwali & 34 & 770 & 667 & $1995-1998$ & 3 & 3 & 0 & občina Bhaktapur \\
\hline Gopikrishna & 10,9 & 292 & 242 & $1995-2002$ & 2 & 4 & 2 & TDPIC \\
\hline Sinamangal & 36 & 1070 & 964 & $1995-2003$ & 4 & 8 & 4 & TDPIC \\
\hline Sinchitar & 26,9 & 920 & 812 & $1996-2003$ & 4 & 7 & 3 & TDPIC \\
\hline Lubhu & 13,5 & 243 & 207 & $1993-1996$ & 2 & 3 & 1 & TDPIC \\
\hline Bagmati Corridor & 9,8 & 258 & 239 & $1992-2001$ & 2 & 9 & 7 & TDPIC \\
\hline Skupno & 239,55 & 7.184 & 5.980 & & & & & \\
\hline
\end{tabular}

Opomba: KVTDC = odbor doline Katmandu za mestni razvoj; TDC = odbor za mestni razvoj (ang. Town Development Committee); TDPIC = odbor za izvajanje načrtov mestnega razvoja (ang. Town Development Plan Implementation Committee); KMC = metropola Katmandu (ang. Kathmandu Metropolitan City), MPPW = ministrstvo za prostorsko načrtovanje in delo (ang. Ministry of Physical Planning and Works).

Vir: KVTDC (1999); urad za mestni razvoj in gradnjo (2003) 
fazi trženja in prodaje. Leta 2007 je bilo v Katmanduju za odobritev prijavljenih vsaj 16 večstanovanjskih zgradb in štirje stanovanjski projekti. Nepremičninska podjetja ugotavljajo, da je težko razvijati obsežne stanovanjske programe zaradi birokracije, ki je povezana s tem: na ministrstvu za prebivalstvo in okolje morajo pridobiti oceno vplivov na okolje, od KVTDC načrtovalska dovoljenja in od občine gradbena dovoljenja. Taki zastoji povzročajo negotovost $\mathrm{v}$ nepremičninski industriji in visoke stroške stanovanjske gradnje.

Skoraj vsa stanovanjska naselja zasebnega sektorja so bila zgrajena $\mathrm{z}$ uporabo armiranobetonskih konstrukcij, poleg tega so bila zraven zgrajena tudi parkirišča. Električno napeljavo in telefonske linije sta priskrbela nepalski urad za elektriko in nepalska družba za telekomunikacije. Voda se je črpala iz podtalnih virov. Odvisno od kakovosti naselja in ciljnih skupin pa so bili zgrajeni tudi drugi objekti, kot so bazeni, telovadnice, savne in prostori z masažnimi kadmi v stanovanjskih kompleksih. Ustanovljeni so bili odbori stanovalcev za ravnanje $s$ trdnimi odpadki in vzdrževanje stavb.

\section{Slabosti načrtovane rabe zemljišč in gradnje stanovanj}

Vladni programi načrtovane rabe zemljišč in zasebna gradnja stanovanj so pozitivno vplivali na gradbeno industrijo, povečali splošno osveščenost javnosti $\mathrm{v}$ zvezi z načrtovanim prostorskim razvojem in do neke mere razvili prostore, ki ustrezajo sodobnemu življenjskemu slogu. Vendarle pa imajo ti programi določene slabosti s stališča načrtovanja in izvajanja. Prvič, velikost in obseg stanovanjskih programov in projektov skupnega urejanja zemljišč, ki jih izvajajo javni organi (KVTDC in občine), ne zadovoljita stanovanjskih potreb v dolini. Javni sektor je v zadnjih dveh desetletjih in pol (1977-2003) pozidal le 8.095 novih stanovanjskih parcel (7.184 v sklopu programov skupnega urejanja zemljišč in $911 \mathrm{v}$ sklopu programov za prostor in storitve). V Katmanduju je bilo od leta 1999 do leta 2001 letno izdanih 3.619 gradbenih dovoljenj (Shrestha, 2006). Že samo da bi zadostili potrebam po zemljiščih za gradnjo stanovanj v dolini, bi bilo do leta 2011 treba zagotoviti okrog 409,12 hektarja letno. Vendar pa je vsako leto na voljo le 15,97 hektarja zemljišč, kar pomeni, da bo do leta 2011 razpoložljivih samo okrog 127,76 hektarja zemljǐ̌č (preglednica 3). Podobno tudi ponudba stanovanj na tržišču še zdaleč ne zadosti letnim potrebam po 24.547 stanovanjskih enotah. $\mathrm{Za}$ - radi vse večjega povpraševanja, premajhne ponudbe, izjemno visokih stroškov zemljiišc in gradnje ter zakonov o dedovanju omejuje razdrobljeno lastništvo celovit in okrepljen prostorski razvoj (Joshi, 1999).

Drugič, pri vseh projektih skupnega urejanja zemljišč so splošni načrti, velikost uličnih blokov in infrastruktura (na primer zahteve, povezane s širino cest in z odprtimi prostori, vključno z zahtevanimi deleži zemljišč v te namene) postali odvisni od posamezne lokacije, o njih pa odločajo lastniki, namesto da bi bili določeni na podlagi dejanskih potreb. Potreba po ohranjanju samozadostnega financiranja projekta in pritiski lastnikov zemljišč, ki zahtevajo čim večji izkupiček, so pomembno zmanjšali obseg odprtih prostorov in javnih zgradb. Pravzaprav je načrtovanje omejeno na spreminjanje parcel nepravilnih oblik v pravilne, pri čemer se vsaki zagotovi tudi dovozno cesto, primerno za vozila. Lastniki zemljišč so bili pripravljeni sodelovati pri projektu Bagmati Corridor šele, ko je bil sprejet dogovor za ukinitev dodelitve odprtih prostorov v prvotnem načrtu. Prostorsko načrtovanje ni enoten postopek in tako je gradnja hiš in njihova uporaba odvisna le od potreb posameznikov in tržnih pogojev. Zaradi prevlade stanovanjske rabe z malo podpornimi funkcijami in družbeno-kulturnimi ugodnostmi so načrtovane soseske monotone, sterilne in brez družabnega življenja. Poleg tega je priložnostno odpiranje trgovin in osnovnih šol v stanovanjskih zgradbah povzročilo več drugih problemov.

Tretjič, skoraj vse stanovanjske soseske, ki jih gradita javni in zasebni sektor, so načrtovane ločeno, brez upoštevanja obstoječe okolice (Shrestha, 2005). Cestna omrežja niso dobro načrtovana, ulični bloki v Kulesworu so preveliki in križišča v Gongabu niso primerna za intervencijska vozila (na primer gasilske ali rešilne avtomobile). V primeru naselja Sun Rise Home je bilo otroško igrišče postavljeno med parkirišča, pod visokonapetostni električni vod, torej na območje, ki ni bilo primerno za gradnjo stanovanj. Bruto gostota prebivalstva $\mathrm{v}$ teh naseljih je prenizka (159 oseb na hektar v stanovanjskem naselju Kuleswore in 143 oseb na hektar v Gongabu) v primerjavi z minimalno bruto gostoto 300 oseb na hektar, ki jo priporoča razvojni načrt doline Katmandu za leto 2020. Čeprav imajo zasebna stanovanjska naselja zmerno bruto gostoto prebivalstva (356 oseb na hektar v naselju Sun Rise Home v Lalitpuru), postopki delitve zemljišč in gradnje stavb pa potekajo na centralni ravni, so se ta naselja zaradi pomanjkanja družabnih in verskih dejavnosti v stanovanjskih kompleksih ter

Preglednica 3: Razlika med povpraševanjem in ponudbo zemljišč za stanovanjske enote

\begin{tabular}{lcccc} 
& \multicolumn{2}{c}{ Letna proizvodnja } & \multicolumn{2}{c}{ Proizvodnja do leta 2011} \\
\cline { 2 - 5 } & povpraševanje & ponudba & povpraševanje & ponudba \\
\hline zemljišča & 409,12 ha & 15,97 ha & 3,273 ha & 127,76 ha \\
\hline stanovanjske enote & 24.547 enot & 479 enot & 196.376 enot & 3.832 enot \\
\hline
\end{tabular}


zavarovanih vhodov preoblikovala $\mathrm{v}$ nekakšna spalna naselja ali »črne skrinjice« (izolirane mestne/družbene skupnosti). Prebivalci teh stanovanjskih naselij preprosto ne kupijo samo hiše, ampak morajo biti pripravljeni sprejeti tudi »življenjski slog «, ki je značilen za določeno naselje.

Četrtič, lokalni lastniki zemljišč so imeli korist od vseh programov pozidave zemljišč in zasebnih stanovanj v dolini, ki zadovoljujejo potrebe družin iz srednjih in višjih dohodkovnih razredov (slika 2). Čeprav je bil stanovanjski projekt Kuleswore namenjen delavcem z nižjimi dohodki, so zaradi številnih lukenj v gradbenem postopku komunalno opremljeno zemljišče lahko kupili tudi višji državni uslužbenci. Še dolgo po koncu projekta ostaja precejšen odstotek zemljišč praznih (6 let po koncu projekta je praznih $23 \%$ parcel v Gongabu), ker lastnike še vedno žene želja po dobičku in so pripravljene parcele že večkrat prodali zaradi kapitalskih dobičkov, ki jih pridobijo $s$ takimi transakcijami, ne da bi na parcelah tudi dejansko zgradili stanovanja. Tržna vrednost komunalno opremljenega zemljišča, ki so ga lastniki dobili nazaj, se je povečala od 300 do $600 \%$ (Karki, 2004).

Vladne agencije novim načrtovanim območjem priskrbijo elektriko, telefonsko povezavo in vodo. $\mathrm{V}$ nasprotju s tem pa mora revno mestno prebivalstvo, ki živi na izoliranih območjih, samo kriti stroške izgradnje dovoznih cest, greznic in suhih vodnjakov. Pred nekaj leti so stroški zasebnih stanovanj znašali od 600.000 NPR do 5.200.000 NPR, odvisno od skupne površine, lokacije, sloga, uporabljenih materialov, kakovosti infrastrukture in drugih objektov. $\mathrm{V}$ zadnjih letih so cene zelo narasle. $\mathrm{Na}$ primer stanovanja $\mathrm{v}$ večstanovanjski stavbi THC Tower III v Panipokhariju, ki jo je zgradilo podjetje Comfort Housing, stanejo od 5.900.000 do 9.300.000 NPR, cene v naselju visokih blokov Guna Colony v Sinamangalu, pa se gibljejo med 3.400.000 NPR $\left(79 \mathrm{~m}^{2}\right)$ in 3.900.000 NPR $\left(84 \mathrm{~m}^{2}\right)$ za trisobno stanovanje. $\mathrm{V}$ državi, v kateri znaša dohodek na prebivalca okrog 270 USD, te cene močno presegajo zmožnosti mnogih Nepalcev. Razmerje med ceno hiše in dohodki v Katmanduju je 10,6 (to pomeni, da je cena stanovanja desetkrat višja od letnega dohodka povprečnega gospodinjstva), tako da si četrtina prebivalstva Katmanduja z dohodkom v gospodinjstvu, nižjim od 6.000 NPR, ne more privoščiti zasebnega stanovanja.

Leta 1992 je začela delovati nepalska finančna družba za gradnjo stanovanj, veliko finančnih ustanov pa je posameznikom začelo dajati posojila za nakup, gradnjo ali obnovo hiš. Trenutno v Nepalu posluje 17 komercialnih bank, 58 finančnih družb in 14 razvojnih bank (Prarthana, 2004). Vsaka ponuja široko paleto stanovanjskih kreditov za posameznike in tudi za gradbene investitorje z dolgoročnimi dobami odplačevanja (preglednica 4). Vendar pa nudijo le malo pomoči skupinam z nižjimi dohodki, ker te skupine nimajo ničesar, kar bi lahko v banki zastavile pod hipoteko. Nepalska stanovanjska in trgovska finančna družba ponuja stanovanjske kredite vsem dohodkovnim skupinam, s posameznimi stanovanjskimi krediti od 300.000 NPR do 500.000 NPR s petletnim obdobjem odplačevanja. Ta posojila pa niso na voljo revnim mestnim prebivalcem, ker mora biti dohodek posojilojemalca trikrat večji od mesečnega obroka odplačevanja kredita. Taka posojila pa glede na trenutne tržne cene zadostujejo samo za nakup kopalnic.

Nove visoke večstanovanjske zgradbe in druga stanovanjska območja, ki so jih zgradila številna zasebna podjetja, so povzročili nove probleme. Anketa, opravljena med najemniki v nekaterih od teh dokončanih stanovanjskih naseljih, je pokazala, da večina stanovalcev prihaja iz elitnih skupin, ki so že kupili hiše v dolini. Zaradi varnostnih razlogov so svoje hiše oddali $\mathrm{v}$ najem in se nato preselili v stanovanjska naselja in stanovanja. Drugi so ta stanovanja kupili kot naložbo za v prihodnje. Pravzaprav nepremičninska industrija tako ponuja poslovno priložnost tistim, ki imajo denar, ne pa rešitve stanovanjskih potreb v dolini. $\mathrm{V}$ večini primerov kupci postanejo le lastniki stanovanja, ne pa tudi zemljišča. Če bi prišlo do potresa in bi se stavba porušila, nihče od lastnikov ne bi mogel zahtevati zemljišča. Večina teh stanovanj nima urejenih zasilnih pro-
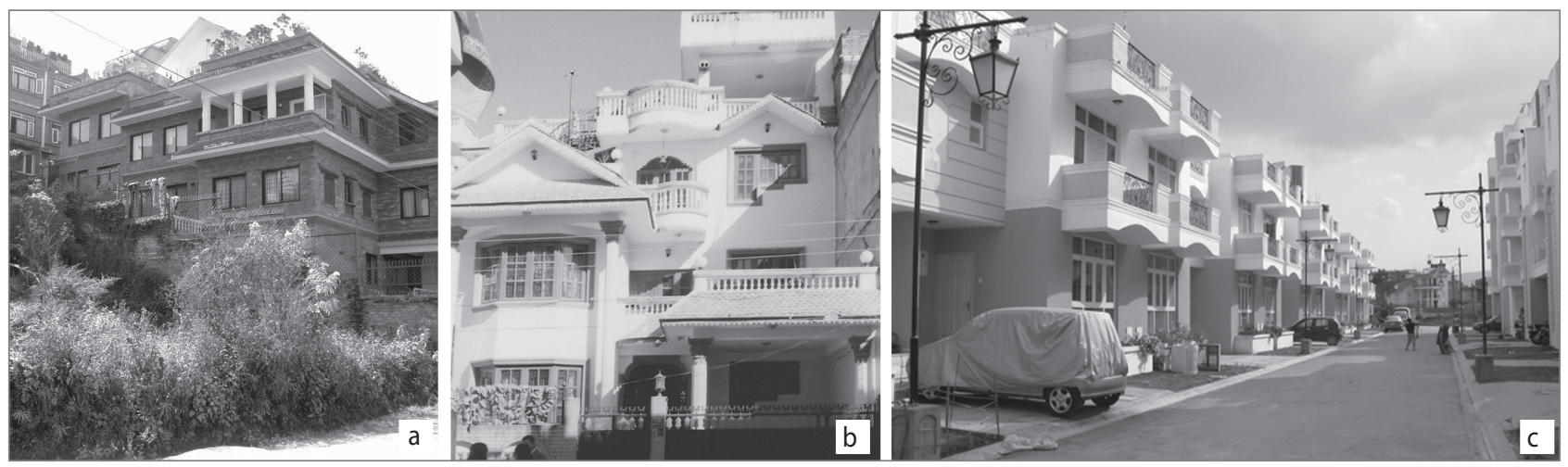

Slika 2: Načrtovana naselja, ki so bila namenjena le za gospodinjstva z visokimi dohodki: (a) nova vila $v$ Kulesworu, (b) vila $v$ Gongabu, (c) stanovanja v naselju Sun Rise Home (foto: Bijaya K. Shrestha). 
Preglednica 4: Stanovanjska hipotekarna posojila različnih bank

\begin{tabular}{|c|c|c|c|c|c|c|c|c|}
\hline Ime banke & $\begin{array}{l}\text { Namen } \\
\text { posojila }\end{array}$ & $\begin{array}{c}\text { Št. } \\
\text { posojil }\end{array}$ & $\begin{array}{l}\text { Posojilna } \\
\text { doba } \\
\text { (minimalno } \\
\text { št. let) }\end{array}$ & $\begin{array}{l}\text { Obrestna } \\
\text { stopnja }\end{array}$ & $\begin{array}{l}\text { Odstotek } \\
\text { finan- } \\
\text { ciranja }\end{array}$ & Jamstvo & Vrsta posojila & Merila \\
\hline $\begin{array}{l}\text { Everest } \\
\text { Bank }\end{array}$ & $\begin{array}{l}\text { nakup/ } \\
\text { gradnja/ } \\
\text { obnova }\end{array}$ & 1.036 & 15 & $9-9,75 \%$ & $75 \%$ & $\begin{array}{l}\text { stvarno, } \\
\text { osebno } \\
\text { jamstvo }\end{array}$ & $\begin{array}{l}\text { enaki mesečni } \\
\text { obroki (EMI) }\end{array}$ & $\begin{array}{c}\text { Mesečni zaslužek mora } \\
\text { biti dvakrat večji od } \\
\text { EMI. }\end{array}$ \\
\hline $\begin{array}{l}\text { Nepal } \\
\text { Investment } \\
\text { Bank }\end{array}$ & $\begin{array}{l}\text { nakup/ } \\
\text { gradnja/ } \\
\text { obnova }\end{array}$ & 31 & 15 & $11,5 \%$ & $70 \%$ & $\begin{array}{l}\text { stvarno, } \\
\text { osebno } \\
\text { jamstvo }\end{array}$ & $\begin{array}{l}\text { enaki mesečni } \\
\text { obroki (EMI) }\end{array}$ & $\begin{array}{l}\text { Potrdilo o plači z raz- } \\
\text { položljivim dohodkom, } \\
\text { ki znaša vsaj } 25 \% \text { več } \\
\text { kot EMI. }\end{array}$ \\
\hline $\begin{array}{l}\text { Kumari } \\
\text { Bank }\end{array}$ & $\begin{array}{l}\text { nakup/ } \\
\text { gradnja/ } \\
\text { obnova }\end{array}$ & 250 & 15 & $11 \%$ & $60 \%$ & $\begin{array}{l}\text { stvarno, } \\
\text { osebno } \\
\text { jamstvo }\end{array}$ & $\begin{array}{c}\text { enaki mesečni } \\
\text { obroki (EMI) }\end{array}$ & $\begin{array}{c}\text { Mesečni zaslužek mora } \\
\text { biti dvakrat večji od } \\
\text { EMI. }\end{array}$ \\
\hline $\begin{array}{l}\text { ACE } \\
\text { Finance }\end{array}$ & $\begin{array}{l}\text { nakup/ } \\
\text { gradnja/ } \\
\text { obnova }\end{array}$ & l & 20 & $\begin{array}{c}10,5- \\
11,5 \%\end{array}$ & $70 \%$ & $\begin{array}{l}\text { stvarno, } \\
\text { osebno } \\
\text { jamstvo }\end{array}$ & $\begin{array}{l}\text { enaki mesečni } \\
\text { obroki (EMI) }\end{array}$ & potrdilo o plači \\
\hline $\begin{array}{l}\text { Development } \\
\text { Credit } \\
\text { Bank Ltd. }\end{array}$ & $\begin{array}{l}\text { nakup/ } \\
\text { gradnja/ } \\
\text { obnova }\end{array}$ & 35 & 15 & $\begin{array}{c}10,5- \\
11,5 \%\end{array}$ & do $90 \%$ & $\begin{array}{l}\text { stvarno, } \\
\text { osebno } \\
\text { jamstvo }\end{array}$ & $\begin{array}{c}\text { enaki mesečni } \\
\text { obroki (EMI) }\end{array}$ & potrdilo o plači \\
\hline
\end{tabular}

Vir: Prarthana (2004)

storov. Na primer, če bi v desetem nadstropju stanovanjskega bloka prišlo do požara, reševanje ne bi bilo mogoče, ker gasilska oprema za gašenje požarov ne more brizgati vode višje kot do petih nadstropij. Gradnja gosto posejanih visokih stanovanjskih zgradb brez upoštevanja prostorske zmogljivosti doline bo povzročila prenatrpanost mesta in prometne zastoje ter močno obremenila obstoječo šibko infrastrukturo, kot je oskrba z vodo in elektriko. Gradnja dragih stanovanj ter številnih trgovskih kompleksov in veleblagovnic v dolini je bogato elito prostorsko ločila od revnega mestnega prebivalstva (Kobayashi, 2006).

\section{Pravni in institucionalni okvir}

Oskrba z načrtovanimi stanovanji v dolini Katmanduja ne bi smela biti omejena na pozidavo zemljišč in gradnjo stanovanj, temveč je na to treba gledati v širšem okviru urbanega razvoja in urbanizacije doline. Pravzaprav je v upravljanje stanovanj in urbani razvoj v Nepalu vključenih več javnih organov. Na državni ravni in ravni sprejemanja strategij sta ministrstvo za prostorsko načrtovanje in delo ter urad za mestni razvoj in gradnjo stavb odgovorna za oblikovanje potrebnih zakonov in smernic za urejanje stanovanjske in urbane rasti. Odbori za mestni razvoj in občine te smernice in programe izvajajo na lokalni ravni. Prav tako obstaja več agencij za oskrbo z vodo, gradnjo cest, elektriko in telefonijo, pri čemer vsaka od teh storitev neposredno pomaga pri razvoju mestnih območij. Ministrstvo za lokalni razvoj skrbi za proračunsko in administrativno upravljanje občin.
Sodelovanje vlade na treh področjih - pri načrtovanju pomoči, oblikovanju zakonov in smernic ter izvajanju projektov pozidave zemljišč in gradnje stanovanj - pa ni zadovoljivo. Pomanjkanje državne urbanistične politike, neuspešno uravnavanje hitre urbanizacije in neobstoj splošnih razvojnih načrtov $\mathrm{v}$ dolini omejujejo prizadevanja javnih in zasebnih sektorjev za zagotavljanje stanovanj. Šele v sedmem razvojnem načrtu (1985-1990) je vlada prvič potrdila, da so stanovanjske razmere ena od osnovnih potreb v okviru socialnega varstva, tako da je leta 1988 ustanovila ministrstvo za stanovanjsko in prostorsko načrtovanje (zdaj ministrstvo za prostorsko načrtovanje in delo) ter istega leta sprejela tudi nov zakon o razvoju mest (kraljeva vlada, 1988). Do pred kratkim je bila vlada nagnjena $\mathrm{k}$ temu, da je stanovanjske razmere obravnavala kot socialni problem in ne kot razvojno dejavnost, ki lahko blagodejno vpliva na gospodarstvo.

Čeprav je zakon o mestnem razvoju iz leta 1988 pooblastil KVTDC, da pripravi načrtovalske standarde in smernice urbanističnega projektiranja za gradnjo stanovanj in urbani razvoj, tega v dveh desetletjih še ni naredila. KVTDC in lokalne občine imajo izkušnje z izvajanjem manjših gradbenih projektov, večinoma v povezavi s stanovanjsko gradnjo. Manjkajo številni načrtovalski elementi: pristop urbanističnega projektiranja $\mathrm{v}$ tlorisnih načrtih in stanovanjski gradnji, določitev posebnih lastnosti vsakega območja in njegove okolice, ureditev dobro načrtovanih in med seboj povezanih kratkih ulic in odprtih prostorov za različne namene, določena mera stalnosti v arhitekturnem slogu, ustvarjanje prostorov za druženje in rekrea- 
cijo ter oskrba z javnimi službami v vsaki soseski. Osredotočanje samo na posamezno lokacijo in posledično gradnjo na njej nikoli ne more ustvariti zdravega stanovanjskega okolja (Shrestha, 2007).

Lokalna občina (v okviru ministrstva za lokalni razvoj) izdaja gradbena dovoljenja, KVTDC (v okviru ministrstva za prostorsko načrtovanje in delo) nadzira gradbišča in glavni okrožni častnik (v okviru ministrstva za domove) kaznuje morebitne kršitelje. Slaba upravljavska sposobnost in nezadostno usklajevanje med temi organi sta spodbudila gradnjo neprojektiranih (90 \%) in ilegalnih zgradb (27\%) v Katmanduju in Lalitpuru (centralni statistični urad, 1997). Izvajajo se preproste določbe lokalnih predpisov, kot so omejitve v zvezi $\mathrm{z}$ višino stavb, s tlorisom in pokrivno površino. Večina visokih stanovanjskih stavb, ki so jih zgradila zasebna podjetja, ni niti redno pregledana zaradi kontrole kakovosti niti ne upošteva kakršne koli protipotresne in protipožarne varnostne ukrepe.

V Nepalu ni posebnih zakonov, ki bi urejali odnose med najemodajalci in najemniki. Pogodba med najemodajalci in najemniki je veljavna celo, če ni registrirana pri pristojnem organu. Zakon o najemu je pomanjkljiv, zastarel in napisan močno $\mathrm{v}$ korist najemodajalcev. Zaradi pomanjkanja ustreznega regulativnega mehanizma imajo stanovalci veliko težav z najemodajalci in s sosedi. Včasih morajo plačevati pretirane najemnine ali sprejeti nepravične najemne pogoje brez kakršne koli pravne osnove. Stanovanjski zakon iz leta 2003 je z določbami v zvezi $s$ prenosom lastništva in prodajo stanovanj $\mathrm{v}$ dolini pospešil gradnjo visokih večstanovanjskih stavb, vendar pa ne vsebujejo jasnih predpisov v zvezi s kakovostjo gradnje in varnostnimi ukrepi. Socialni problemi obremenitve s hrupom in motenja s strani sosedov, kot tudi pravočasno popravljanje cevi, ki puščajo, in odpravljanje drugih okvar v zakonu niso jasno določeni. $\mathrm{Za}$ to so trenutno odgovorni odbori stanovalcev.

Državna politika za zavetišča priznava, da so stanovanja za revno mestno prebivalstvo osnovna potreba in da se zagotavljanje stanovanj kot del prizadevanj za zmanjšanje revščine povezuje z državnim gospodarskim razvojem (ministrstvo za stanovanjsko in prostorsko načrtovanje, 1996), vendar vlada še ni izdelala natančnega načrta za njeno izvajanje. Revnega mestnega prebivalstva in brezdomnih družin ni mogoče vključiti v projekte skupnega urejanja zemljiš̌č, ker najemodajalci težijo $\mathrm{k}$ pridobivanju kar največjih dobičkov ob prodaji zemljǐ̌š in ker je treba vzdrževati finančno samozadostnost projektov. Za sodelovanje drugih organov v projektih skupnega urejanja zemljišč ni nikakršne pravne osnove. Podporni sklad za delavce (nep. Karmachari Sanchaya Kosh) zagotavlja finančno podporo vladi, državna finančna družba za stanovanjsko gradnjo, ki je bila ustanovljena leta 1990, pa oskrbuje srednje in višje dohodkovne skupine. Druge komercialne banke in finančne ustanove imajo stroga merila za pridobitev posojil. Revni mestni prebivalci so tako izključeni iz obstoječega finančnega sistema. Zadruge, vključene v programe financiranja revnega mestnega prebivalstva, so po izvoru običajno posamične nevladne organizacije (na primer podporna skupina za zavetišča Lumanti), njihovo delovanje pa se osredotoča bolj na dejavnosti za ustvarjanje delovnih mest, ki so namenjena ženskam, ki živijo v ilegalnih naseljih. Vloga vlade pri pospeševanju gradnje stanovanj pa je povzročila, da so stanovanja za revne mestne prebivalce slabše dostopna in da si jih ti težje privoščijo.

Zakon o lokalnem samoupravljanju iz leta 1999 (kraljeva vlada, 1999) pooblašča lokalne občine, da znotraj občinskih meja pripravljajo, izvajajo in nadzorujejo svoje razvojne načrte. Vendar pa celo po enem desetletju še vedno niso uspele učinkovito prevzeti teh odgovornosti. Večina zemljišč v dolini je $\mathrm{v}$ zasebni lasti, preostanek pa pripada vladi. Zaradi pomanjkanja jasnih politik, operativnih smernic in človeških virov v občinah dodelitev nekaterih parcel in stanovanj znotraj zemljišč zasebnega sektorja z navzkrižnim subvencioniranjem, s spodbudami in sodelovanjem z lokalnimi nepremičninskimi podjetji še ni mogoča. Z vidika urbanističnega razvoja je dolina Katmanduja, ki pokriva manj kot $100 \mathrm{~km}^{2}$ mestnega prostora, samo ena prostorska enota. Vendar pa v dolini deluje pet različnih občin. Sodelovanje v stanovanjskih programih je včasih težko doseči, ker imajo župani različna politična prepričanja. Postopek sprejemanja odločitev in stopnja odgovornosti sta bila $\mathrm{v}$ zadnjih letih ovirana, ker zaradi politične nestabilnosti v občinah ni bilo lokalno izvoljenih županov. Trenutno se občine bolj ukvarjajo s pobiranjem dohodkov in manj z uravnavanjem mestne rasti za doseganje trajnostnega razvoja.

Kljub vsemu temu pa si različne ravni prizadevajo, da bi $s$ politično pomočjo zadovoljili stanovanjske potrebe $\mathrm{v}$ državi. Državna mestna politika iz leta 2007, ki neformalni sektor obravnava kot del urbane ekonomije in ilegalna naselja kot socialni problem, je v izvajanju. Finančno podporo za obsežne programe kapitalskih izboljšav v občinah usmerja sklad za mestni razvoj. Da bi zagotovili večje zavezništvo med različnimi deležniki, vključno $s$ finančnimi donatorji, je bil ustanovljen forum za izboljšanje slumov (ang. Slum Upgrading Forum). Prav tako so občine vključene $\mathrm{v}$ številne programe, kot so kartografiranje revnega prebivalstva (ang. poverty mapping), zbiranje deževnice in zmanjěevanje potresnega tveganja, ki ga izvajajo urad za mestni razvoj in gradnjo objektov, Program Združenih narodov za naselja (ang. United Nations Human Settlemnets Programme - UN-HABITAT) in Razvojni program Združenih narodov (ang. United Nations Development Programme - UNDP). Zakon o pozidavi zemljišč in zakon o nepremičninah sta prav tako v sprejemanju. 


\section{Sklep in priporočila}

Veliko povpraševanje po stanovanjih $\mathrm{v}$ dolini Katmanduja je posledica več dejavnikov, vključno s hitro urbanizacijo, $\mathrm{z}$ nenačrtno rastjo mest in s slabim vzdrževanjem stanovanj $\mathrm{v}$ središču mesta in na njegovem obrobju. Ukrepi, ki jih je vlada dosledno izvajala od 70. let prejšnjega stoletja in so zajemali pozidavo zemljišč in gradnjo stanovanj, oblikovanje različnih smernic, ustanavljanje novih ustanov in vključevanje zasebnega sektorja, so se izkazali za neprimerne in neučinkovite. Projekti skupnega urejanja zemljišč, ki so bili uvedeni v 80. letih, so omejeni na manjše gradbene projekte. Lastniki zemljišč vplivajo na načrtovalske odločitve, ker ni načrtovalskih smernic za projekte skupnega urejanja zemljišč in ker imajo občine le minimalna pooblastila. Vsi dokončani projekti skupnega urejanja zemljišč so bili uspešni le pri financiranju osnovne mestne infrastrukture in pri zagotavljanju koristi lokalnim lastnikom zemljiščc, pri čemer so omogočili le malo izboljšav v smislu ustvarjanja dinamičnega mestnega okolja. Stanovanja, zgrajena po letu 2000 na pobudo zasebnega sektorja, so $s$ finančno podporo komercialnih bank postala »zaprte skupnosti«, namenjene pripadnikom elitnih skupin. Pravzaprav so komunalno opremljena zemljišča in razpoložljiva stanovanja bolj namenjena poslovnim naložbam in ne socialnovarstvenim storitvam ali razvoju skupnosti. $V$ teh okoliščinah je pomembna uporaba strategije s pristopom »od zgoraj navzdol « in tudi »od spodaj navzgor«. Na osrednji ravni je potreben razvoj politik, ki bodo usmerjene v povezovanje stanovanjske gradnje z urbanizacijo (in urbanim razvojem), ter sodelovanje različnih organov in zasebnih sektorjev za zagotavljanje celovitega prostorskega razvoja (vključno z upoštevanjem potreb revnega mestnega prebivalstva in s pripravo načrtovalskih standardov in smernic urbanega projektiranja). Na lokalni ravni mora biti občinam omogočeno, da učinkovito upravljajo vire, usklajujejo delo različnih organov ter spremljajo in nadzirajo načrtovanje in razvoj. Za reševanje trenutnega stanovanjskega primanjkljaja v dolini Katmanduja predlagamo ta strateška priporočila:

(a)Uravnavanje hitre urbanizacije in nenačrtne rasti mest $\mathrm{z}$ oblikovanjem državne urbanistične politike, določitvijo prostorske zmogljivosti doline, decentralizacijo socialnoekonomskih dejavnosti v dolini in razvojem splošnega načrta za celotno dolino.

(b)Zagotovitev vladnega sodelovanja pri vseh vidikih stanovanjske gradnje za povečanje ponudbe cenovno dostopnih stanovanj, vzdrževanje minimalnih stanovanjskih standardov ter povečanje dostopnosti stanovanj za revno mestno prebivalstvo in nižje dohodkovne skupine.

(c) Razvoj načrtovalskih standardov in smernic urbanega projektiranja za vključevanje pozidave zemljišč in gradnje stavb, da bi se oblikovala dinamična mestna okolja znotraj območij skupnega urejanja zemljišč ter zagotovile socialno- varstvene in intervencijske storitve za zasebna stanovanjska naselja. To ne bo samo spodbudilo zasebnega sektorja $\mathrm{k}$ sodelovanju, temveč bo povzročilo tudi razpad monopola lastnikov zemljišč nad zagotavljanjem infrastrukture na teh območjih. Z vključevanjem pristojnih organov, vladnim subvencioniranjem in drugimi podobnimi ukrepi bo zagotovljeno, da bo revno mestno prebivalstvo prejelo določen odstotek komunalno opremljenih zemljišč in stanovanj;

(d)Oblikovanje predloga stanovanjskega zakona za zagotavljanje lastninskih pravic ter izboljšanje in urejanje slumov in ilegalnih skupnosti. Zagotavljanje davčnih spodbud za izboljšanje obstoječih stanovanjskih razmer v dolini;

(e) Spodbujanje mikrofinanciranja in drugih ukrepov za pomoč revnemu mestnemu prebivalstvu pri pridobivanju sredstev za nakup in obnovo stanovanj;

(f)Povečanje pristojnosti lokalnih občin za usklajevanje politik $\mathrm{z}$ regionalnimi načrtovalskimi uradi in vladnimi organi, kot tudi za mobilizacijo virov, združevanje sredstev in programov z lokalnimi nevladnimi organizacijami, organizacijami $\mathrm{v}$ posameznih skupnostih in $\mathrm{s}$ številnimi donatorskimi organi ter nadzor gradnje stanovanj med izvajanjem te.

Bijaya K. Shrestha

S (settlement-society-sustainability) 3 Alliance, Development Forum for Habitat, Katmandu, Nepal

E-pošta: bkshrestha@hotmail.com

\section{Viri in literatura}

Adhikari, A. P. (1998): Urban environmental planning in Nepal: Analysis, policies and proposals. Katmandu, The World Conservation Union.

Backe-Hansen, Olay idr. (1985): Project Kathmandu. Magistrsko delo. Trondheim, University of Trondheim, Norwegian Institute of Technology, Division of Town and Regional Planning.

Center za pomoč nepalskim otroškim delavcem (1999): Voice of Child Workers. CWIN's Quarterly Newsletter, 28. november.

Centralni statistični urad (1997): Nepal living standards survey report. Volume I and II. Katmandu.

Centralni statistični urad (2004): Nepal living standards survey report 2003/04. Vol. I and Vol. II. Katmandu.

Cohen D., Spear S., Scribner R., Kissinger, P., Mason, K., in Wildgen, J. (2000): Broken windows and the risk of gonorrhoea. American Journal of Public Health, 90(2), str. 230-236. DOI: 10.2105/ AJPH.90.2.230

Dunn, J. R. (2002): Housing and inequalities in health: a study of socioeconomic dimensions of housing and self reported health from a survey of Vancouver residents. Journal of Epidemiology Community Health, 56(9), str. 671-682. DOI: 10.1136/jech.56.9.671

Dupuis, A., in Thorns, D. C. (1998): Home, home ownership and the search for ontological security. The Sociological Review, 46(1), str. 24-47. DOI: 10.1111/1467-954X.00088

Garnett, D., Reid, B., in Riley, H. (1991): Housing Finance. Coventry, 
Institute of Housing and Harlow, Longman.

Halcrow Fox Associates idr. (1991): Kathmandu valley urban development plans and programs: Strategy plan for Kathmandu valley. Vol. I: Text. Katmandu, Department of Housing and Urban Development, Ministry of Housing and Physical Planning.

Joshi, J. (1999): Housing and urban development in Nepal. Katmandu, Naveen Press.

Karki, T. K. (2004): Implementation experiences of land pooling projects in Kathmandu valley. Habitat International, 28(1), str. 67-88. DOI: 10.1016/S0197-3975(02)00085-1

Kobayashi, M. (2006): Social change in Kathmandu related with globalisation and liberalisation - potential of new life style and domestic market. Planning Journal of Tokyo University, 44(1), str. 27-38.

Kraljeva vlada (1973): Town development act 1973. Katmandu.

Kraljeva vlada (1988): Town development act 1988. Katmandu.

Kraljeva vlada (1999): Local self-governance act 1999. Katmandu.

Ministrstvo za prebivalstvo in okolje (1999): Environmental planning and management of the Kathmandu valley. Katmandu.

Ministrstvo za stanovanjsko in prostorsko načrtovanje (1988): Guided land development, a proposed implementation methodology. Katmandu.

Ministrstvo za stanovanjsko in prostorsko načrtovanje (1996): National Shelter Policy 1996. Katmandu.

Nacionalna načrtovalska komisija (2002): The Tenth Plan 2002-2007. Katmandu.

Nacionalna načrtovalska komisija (2005): Summary of results on poverty analysis from Nepal living standards survey (2003-04). Katmandu.

Nepalski nacionalni odbor za bivališča (1996): National plan of action. Katmandu.

Odbor doline Katmanduja za mestni razvoj (1999): Status of comparative project features. Katmandu.

Odbor doline Katmanduja za mestni razvoj (2000): Development plan of Kathmandu valley - 2000. Katmandu.

Odbor doline Katmanduja za mestni razvoj (2002): Long term development concept of Kathmandu valley. Katmandu.

Podporna skupina za zavetišča Lumanti (2003): A situational analysis of urban poor communities in Kathmandu and Lalitpur. Katmandu.

Podporna skupina za zavetišča Lumanti in nepalska voda za zdravje (2000): The water supply and sanitation situation of the urban poor in the Kathmandu valley: Results of a research study. Katmandu.

Prarthana, S. (2004): Is enabling enough? Housing finance for low income groups in Kathmandu, Nepal. Tipkopis.

Rabenau, B. (1990): Issues in Housing Development. Kathamndu, Urban Development Through Local Effort.

Raziskovalni center za neformalni sektor (2004): District

development profile of Nepal 2004. Katmandu.
Raziskovalni inštitut Triangle (2001): Willingness to pay for improved water supply in the Kathmandu valley. Katmandu.

Regmi, D. N., in Joshi, D. (1988): Existing sanitary conditions of the households in Kathmandu valley. Katmandu, Ministry of Health.

Shrestha, B. K. (2005): How not to design a neighbourhood - Reviewing different residential precincts of Kathmandu. SCITECH Nepal, A Journal of Scientific and Technical Studies, 8(2), str. 46-69.

Shrestha, B. K. (2006): Land pooling system in the Kathmandu valley - successful in financing infrastructure but failure in achieving urban environment. SCITECH Nepal, A Journal of Scientific and Technical Studies, 9(3), str. 7-19.

Shrestha, B. K. (2007): Planned residential neighbourhood development in Kathmandu valley: Community building or provision of physical infrastructure? Protibesh: Environment, Journal of the Department of Architecture, 11, str. 33-44.

Shrestha, S., in Shrestha, B. K. (2009): The influence of water in shaping culture and modernization of the Kathmandu valley. V: Feyen, J., Shannon, K., in Neville, M. (ur.): Water \& urban development paradigms - Towards an integration of engineering, design and management approaches, str. 183-188. London, CRC Press.

Svetovna zveza za varstvo narave (1995): Regulating growth: Kathmandu valley. Katmandu.

Tanaka, M. (1997): Conditions of low income settlements in Kathmandu: Action research in squatter settlements. Tipkopis.

Thapa, R. B., in Murayama, Y. (2010): Drivers of urban growth in the Kathmandu valley, Nepal: Examining the efficacy of the analytic hierarchy process. Applied Geography, 30(1), str. 70-83. DOI: 10.1016/j.apgeog.2009.10.002

Urad za mestni razvoj in gradnjo (2003): Land pooling: What, why, where and how. Katmandu.

USAID (1994): Carpet relocation study. Katmandu. 